Proceedings

\title{
Personal Memories and Imagery. A Study of Autobiographical Memory through Drawing ${ }^{\dagger}$
}

\author{
Paolo Bozzato \\ Dipartimento di Scienze Teoriche e Applicate, Università degli Studi dell'Insubria, Via Giuseppe Mazzini 5, \\ 21100 Varese VA, Italy; paolo.bozzato@uninsubria.it; Tel.: +39-033-221-8901 \\ + Presented at the International and Interdisciplinary Conference IMMAGINI? Image and Imagination \\ between Representation, Communication, Education and Psychology, Brixen, Italy, 27-28 November 2017.
}

Published: 9 November 2017

\begin{abstract}
The present study investigates autobiographical memory through the use of imagery and a short narrative. A sample of 72 young adults, residing in Italy, were asked to draw a meaningful memory (and to choose a title for it) about their infancy, childhood, pre-adolescence and adolescence. Through the use of special markers, a qualitative-quantitative analysis of the drawings was carried out. The results made it possible to highlight the different elements that gave shape to the Self in a particular period, leaving traces in memory: specific social references, emotions and moods, places, actions, achievements and personal objects.
\end{abstract}

Keywords: autobiographical memory; imagery; drawing; emotions; Self; identity; developmental psychology; life-span psychology

\section{Introduction}

\subsection{Theoretical context}

Human memory can be defined as the ability to store, retain, and retrieve information that is interesting for us [1]. Among memories that are stored in the memory system, there are both personal and autobiographical ones referring to people, events, episodes, objects and relationships that have marked the individual's life experience. Classically, autobiographical memory has been defined as "the ability to remember one's own life" [2,3], and as the neurosciences show, this is a complex cognitive system mediated by neural networks distributed through large areas of neo-cortex and limbic system [4]. Its importance is related to its relationship to Self-building and personal identity, representing the link between what we have been in the past, what we are in the present, and what we want to be in the future. Schachter (1996) argues that the memories of the Self "provide the narrative continuity between the past and the future-a collection of memories that form the core of personal identity" [5] (p. 90).

Traditionally, researchers have focused on the verbal code in the study of autobiographical memory through questionnaires or interviews [6]. The present study uses, instead, a method which is still in an exploratory phase, i.e., drawing intended as an access tool to memory traces and the visual details of personal memories [7,8]. In 1971, Paivio, with his dual-coding theory, argued that mental imagery and verbal structures were two ways of representing and storing information, which cooperate in maintaining encoded material in long-term memory [9]. Kosslyn (1983) emphasized that the figurative format of memory allows us to represent information as a drawing or a photo, showing that people often use mental pictures to retrieve their memories [10]. Even today, several scholars are convinced that memory retrieval is modulated by the ability to recall in detail the set of visual characteristics that were present at the time of the memory trace encoding [11,12]. 
These visual representations, or mental imagery, would help to reactivate non-visual recollections and the emotional and conceptual information related to the memories since they favour their recall in a well-defined space-time context [13]. So it can be said that mental imagery interacts with the system of language and narrative in the recovery of autobiographical memories. This means that despite the fact that imagery is a characteristic trait of autobiographical memory, it would not be sensible to investigate it phenomenologically without utilizing narrative methods. For this reason, we asked the research participants in our study to draw one of their own meaningful memories and to give it a title, that is, a short narrative description. Of course, the fact that personal memories appear in the mind in the form of visual imagery does not guarantee the truthfulness and completeness of the memories. The majority of the contemporary theories believe that a large part of the work of memory consists not so much in the reproduction of the past, but in a real reconstruction that does not always correspond to reality [12,14]. However, whether the memories and their details are accurate representation of past experience or not, does not alter the effects of autobiographical memory on identity-building, since these effects are related to the conviction of the individual that his or her memories in fact are real.

\subsection{Purpose of the Study}

The objectives and the methodology of the study were chosen taking into account the literature above briefly recalled on mental imagery as an access tool of autobiographical memory. First of all, the study intends to enhance the role of mental pictures in the study of autobiographical memory, and not to exclusively consider the importance of verbal language. We started with the hypothesis that asking our research participants to draw their memories and assigning them a title is equivalent to asking them to resort to both mental imagery and narrative thought.

The main purpose of our research work is to analyse, through quantitative and qualitative criteria, in a sample of young adults, the mental pictures of their most meaningful life experience, related to four periods of life: infancy ( $0-5$ years), childhood (6-10 years), pre-adolescence (11-14 years), and adolescence (15-18 years). Although periods of life are called and delimited temporarily in different ways by the researchers, there is a general agreement on the idea that they represent an abstract and general level of autobiographical memories, a sort of container of thematic units (for example: where I was, with whom I was, what I was doing), related to specific stages of life.

Through this study we also want to contribute to the research on how people recall personal memories, by comparing the various periods of life considering three different variables: ease, pleasantness, and speed in the recall of memories.

\section{Materials and Methods}

The research was conducted on a sample of 72 individuals attending a university lesson (in a Communication studies course), mostly female (53 women and 19 men) with an average age of 22.6 years (S.D. 5,6). Except in two cases, the participants were Italian nationals. An anonymous questionnaire, consisting of four panels (referred to the four ages of life that were considered for the research), was given to them. For each panel it was required:

1. to draw, in pencil, one of their meaningful autobiographical memories;

2. to assign a title to the memory;

3. to answer the question: "How was the recovery of this memory?" through a semantic differential [15], consisting of three pairs of opposite adjectives (easy/difficult, pleasant/unpleasant, fast/slow), placed at the extremities of 7 points graduated scales.

The research subjects were told that it was not necessary to have special artistic skills to participate in the data collection, but to draw as they were able to, the important thing was to recognize that memory as meaningful. No other information was provided and a maximum time of thirty minutes was allowed to complete the questionnaire. The analysis of the drawings has provided several phases: 
1. specific indicators or markers were selected partly from the works of Jerome Bruner $[16,17]$ and previous research $[7,18]$, and partly introduced for the first time;

2. depending on the presence or absence in the drawing of the pre-selected indicators, the results were divided in different categories by three independent judges with degree in Human Sciences and alien to the objectives of the study. The judges conducted the categorization separately, the results were then compared and the disagreements (less than 10\%) mediated through a collective discussion. To ensure that the agreements were not due to chance, Cohen's Kappa coefficient was computed by comparing the judges two by two [19]. In all three cases, $\mathrm{k}$ values were higher than random patterns $(p<0.01)$;

3. a descriptive statistic of the different category indicators was prepared by calculating frequencies and percentages;

4. a statistical analysis of the answers to the semantic differential was carried out using Student's $t$-test for paired samples.

\section{Results and Discussion}

A very first important result is the total number of autobiographical memories recalled through the methodology employed: 286 drawings were made, most of which are rich in details that only graphic representation can communicate in such a precise and immediate way (such as, the symbol put on the personal kindergarten cabinet, or the checked blanket in the bedroom of the mountain house). Much of the drawings look like photographic shots, and make us think of the use of real mental pictures that give shape to the memories, confirming Greenberg and Rubin's (2003) model that the most important component of autobiographical memory is visual imagery [13].

Significant is the fact that all research participants recalled and graphically represented a meaningful memory of the first five years of life, the period of so-called "childhood amnesia" [20,21]. Only $16.7 \%$ of the individuals rated it as difficult to recover that memory, while for $79.2 \%$ of them it was easy (about half of the respondents stated even "very easy"), while $4.1 \%$ preferred not to take a position. As already mentioned, however, there is a broad consensus among psychologists to consider human memory a reconstruction of the past and not necessarily a true copy of reality. The knowledge of what happened in one's early years of life can result from other sources that are not his or her own memory (parents' tales, photos, etc.), even when people actually believe they remember.

In all the periods of life considered by our study, the most represented were those that Conway and Rubin (1993) call "general events" [22], which range from an hour to a day, as exemplified by the titles of the drawings: "at the playground with my grandmother", "sea holidays", "going out on my motorcycle", "my high school diploma examination". Also "first time memories" appear frequently in the drawings, such as "my first day of school", "my first time camping holiday", "the first time I met my boyfriend." As Robinson (1992) pointed out, memories of early experiences provide the structure of autobiographical memory, organizing the personal stories in units and helping to establish cause-effect relationships [23]. They are also used to evaluate the Self and one's past experience, or for a prospective evaluation (we define who we are and want to be on the basis of what we have been and how the first experiences which we had were).

We report, in Table 1, the pre-selected markers partly derived from the work by Bruner (1998) and employed in Italy by a growing number of researchers that use as their method both narrative and drawing $[7,18]$. Only the indicators "place" and "meaningful object" were introduced for the first time on the basis of our preliminary analysis of the drawings. 
Table 1. List of markers used in our study.

\begin{tabular}{ll}
\hline Marker category & Description \\
\hline Self-depiction & Presence of the subject in the drawing \\
\hline Place & Physical background or landscape \\
\hline Qualia & Mood and emotion details \\
\hline Social References Agency & $\begin{array}{l}\text { Important people (family, friends, peers, teachers, etc.) or pets } \\
\text { Activities done by the subject }\end{array}$ \\
\hline Commitment & The commitment of the subject in a task or responsibility \\
\hline Meaningful Object & Meaningful object for Self-definition \\
\hline
\end{tabular}

We calculated the frequencies and percentages of the 7 markers mentioned above for each period of life considered. In regards to the presence of the Self-depiction marker, Table 2 shows that most of the sample chose to represent themselves in the drawings (with percentages between $77.5 \%$ and $68.1 \%$ in the different ages). Only a minority of the participants (28\%) chose not to appear in the drawings, taking an external position in the memory, comparable to the one who takes a photo: present in the scene but not in the picture.

Table 2. Marker "Self-depiction in the drawing": percentages on the total number of the drawings (286).

\begin{tabular}{lccccc}
\hline & Infancy & Childhood & Pre-Adolescence & Adolescence & Total \\
\hline Presence of Self-depiction & $72.2 \%$ & $68.1 \%$ & $77.5 \%$ & $70.4 \%$ & $72 \%$ \\
Absence of Self-depiction & $27.8 \%$ & $31.9 \%$ & $22.5 \%$ & $29.6 \%$ & $28 \%$ \\
\hline
\end{tabular}

As revealed by a Robinson and Swanson study (1990), the sense of belonging experienced to own autobiographical memories, as well as the emotional involvement in them, is a quality that varies from person to person [23]. For those who face radical changes in their lives it is more difficult to recognize themselves in their autobiographical memories and-we can hypothesize-to represent themselves in the drawing. In this regard, another interesting result comes from the analysis of the marker "Qualia" that indicates the expression of emotions and moods by the characters of the drawings. They were identified through some parts of the drawing (characters' facial mimicry and posture or symbols, such as the hearts between two characters), often confirmed by the picture title (for example: "a sad party", "bad news", etc.). As shown in Table 3, approximately half of the sample chose to represent emotions and moods in their drawings (with minimal differences between different periods of life, and between $52.9 \%$ and $42.9 \%$ ), confirming the literature that considers the emotional component central in autobiographical memories. It is assumed that it has the important function of organizing personal experiences [24,25].

Table 3. Marker "Qualia": percentages on the total number of the drawing (286).

\begin{tabular}{cccccc}
\hline & Infancy & Childhood & Pre-Adolescence & Adolescence & Total \\
\hline Presence of Qualia & $47.9 \%$ & $45.1 \%$ & $42.9 \%$ & $52.9 \%$ & $52.8 \%$ \\
Absence of Qualia & $52.1 \%$ & $54.9 \%$ & $57.1 \%$ & $47.1 \%$ & $47.2 \%$ \\
\hline
\end{tabular}

Although it may only be one of the factors involved in the formation and recovery of autobiographical memories, emotional intensity fixes memory traces in the memory system and makes them more vivid over time. It can be assumed that personal meaningful events with high emotional intensity help to give a sense of continuity to one's own life story, producing emotional landmarks for the organization of autobiographical memory. In our study we found that those memories with a high emotional intensity were often accompanied by a large number of details in the drawing, almost reproducing the vividness of the memory trace. For example, Figure 1 shows a drawing referring to infancy entitled "In the car with my dad, while it rained heavily and we listened 
to music". The strong emotional activation of the characters is clear thanks to the facial expressions and the child (the drawer) that raises her arms (maybe to move them to the rhythm of music).

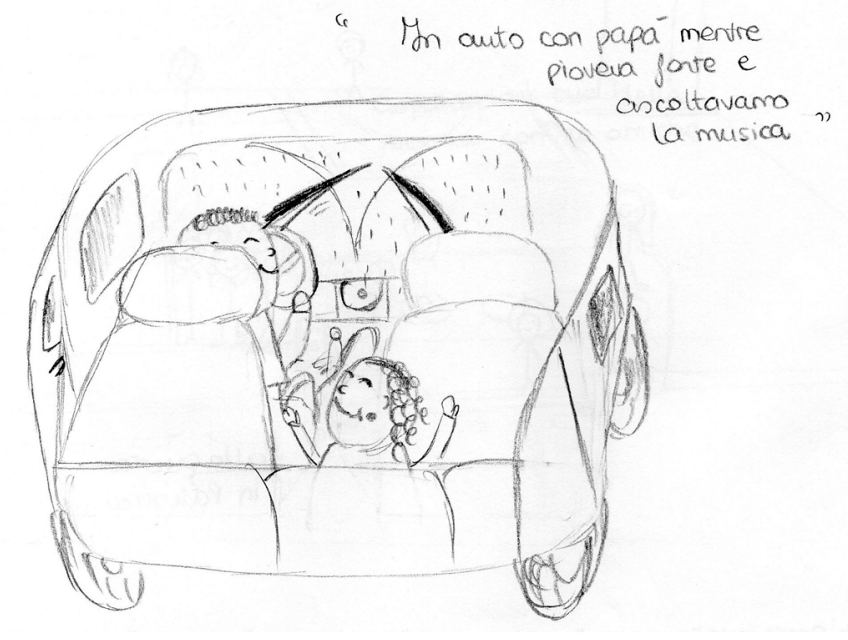

Figure 1. Drawing, referring to infancy, entitled "In the car with my dad while it rained heavily and we listened to music".

Passing on analysing social references, 388 people (in addition to the drawer) and 7 pets were represented in the drawings. Children and teenagers consider pets as members of their family or little friends, so we included them in the social references important for the Self-construction.

In Table 4 we observe that in the first years of life memories prevail the ones relating to one's family members (parents, but also brothers, sisters, grandparents and the family as a whole). In fact, in infancy and childhood the Self takes shape essentially in what Bronfenbrenner and Morris (2006) define as a "family microsystem", so it is not surprising that members of the family often appear in the autobiographical memories related to this life stage [26]. Considering the different ages all together, friends and classmates are the social references most frequently drawn by our sample (with a percentage of $36.5 \%$ ), reaching even $63.6 \%$ in pre-adolescence, which is the period when the group of peers usually acquires greater importance than the family and other adults. In adolescence, friends and first boyfriends/girlfriends are the most drawn (each of these social references reach the percentage of almost $38 \%$ ).

Table 4. Marker "Social References": percentages on the total number of the drawings assigned to this indicator (295).

\begin{tabular}{cccccc}
\hline & Infancy & Childhood & Preadolescence & Adolescence & Total \\
\hline Family (parents and siblings) & $17.4 \%$ & $6.9 \%$ & $4.5 \%$ & $10.3 \%$ & $11.1 \%$ \\
Mother & $6.5 \%$ & $0 \%$ & $4.5 \%$ & $0 \%$ & $3.2 \%$ \\
Father & $13 \%$ & $6.9 \%$ & $0 \%$ & $0 \%$ & $6.3 \%$ \\
Siblings & $23.9 \%$ & $0 \%$ & $4.5 \%$ & $0 \%$ & $9.5 \%$ \\
Grandparents & $17.4 \%$ & $13.8 \%$ & $0 \%$ & $0 \%$ & $9.5 \%$ \\
Friends and schoolmates & $10.9 \%$ & $55.2 \%$ & $63.6 \%$ & $37.9 \%$ & $36.5 \%$ \\
First boyfriends/girlfriends & $0 \%$ & $0 \%$ & $4.5 \%$ & $37.9 \%$ & $9.5 \%$ \\
Teachers & $0 \%$ & $10.3 \%$ & $9.1 \%$ & $3.4 \%$ & $4.8 \%$ \\
Others ${ }^{1}$ & $4.3 \%$ & $3.4 \%$ & $4.5 \%$ & $3.4 \%$ & $3.2 \%$ \\
Pets & $6.5 \%$ & $3.4 \%$ & $4.5 \%$ & $6.9 \%$ & $5.5 \%$ \\
\hline
\end{tabular}

${ }^{1}$ Babysitters, uncles and aunts, cousins, nephews/nieces.

In Figure 2, in a drawing related to the childhood of a young woman, we are witnessing the reconstruction of a multitude of details during a party celebrating her "tenth birthday with friends and family". The child (in front of the cake which has the shape of a face with candles), surrounded 
by peers, while her parents admire the scene. And then we can see a table full of food and beverage, and all the decorations of the room. The characters' mimicry clearly express joy.

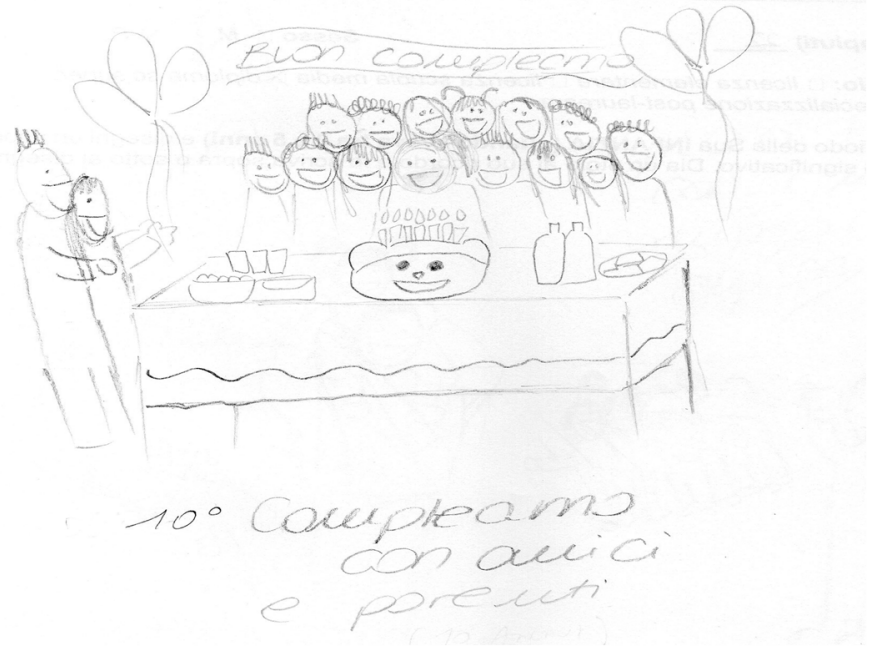

Figure 2. Drawing, referring to childhood, entitled "My tenth birthday with my friends and family".

Even in the diversity of theoretical positions, almost all psychologists today agree in attributing to the physical and social context a great importance in the building of the Self and personal identity. It seemed therefore interesting to analyse, in addition to social references, the places represented by our research participants. It is plausible to think that not all places have the same importance for the individuals in their own life story and for their sense of personal identity, so we can assume that some places are to be remembered as more meaningful than others. In our study, without being explicitly required, 116 places were clearly drawn by the participants. In $28.6 \%$ of cases, the university students chose to represent a place as a memory in itself and as a container of various significant experiences (as simplified by the titles of the drawings: "the school I attended", "my old house" etc.). In the remaining $71.4 \%$ of cases, the place is the context in which the characters are represented. As it can be seen in Table 5, considering the different ages together, educational structures and schools (31\%) prevail, followed by holiday locations ( $25 \%$ in the overall sample, but even $50 \%$ in adolescence).

Table 5. "Places remembered and drawn": percentages on the total number of the drawings assigned to this indicator (116).

\begin{tabular}{cccccc}
\hline & Infancy & Childhood & Pre-Adolescence & Adolescence & Total \\
\hline Kindergartens and schools & $40.6 \%$ & $27.5 \%$ & $30.8 \%$ & $22.2 \%$ & $31 \%$ \\
Own house & $12.5 \%$ & $12.5 \%$ & $0 \%$ & $0 \%$ & $3.4 \%$ \\
Grandparents' house & $3.1 \%$ & $7.5 \%$ & $3.8 \%$ & $5.5 \%$ & $8.6 \%$ \\
Holiday locations & $15.6 \%$ & $17.5 \%$ & $30.8 \%$ & $50 \%$ & $25 \%$ \\
Swimming pools & $3.1 \%$ & $15 \%$ & $0 \%$ & $5.5 \%$ & $6.9 \%$ \\
Parish Sunday School & $0 \%$ & $2.5 \%$ & $7.7 \%$ & $0 \%$ & $2.6 \%$ \\
Shop & $0 \%$ & $2.5 \%$ & $0 \%$ & $11.1 \%$ & $2.6 \%$ \\
Sports fields & $0 \%$ & $10.3 \%$ & $9.1 \%$ & $3.4 \%$ & $4.8 \%$ \\
Others 1 & $4.3 \%$ & $3.4 \%$ & $4.5 \%$ & $3.4 \%$ & $3.2 \%$ \\
\hline
\end{tabular}

${ }^{1}$ Hospital, gym, ballet school, cinema, bus stop, car cabin.

The school, with its various environments (sometimes represented in detail, such as a particular corridor, the classroom, the school canteen and the garden of the school where recreation time was spent), is in fact the space in which children and teens spend several hours of their lives. It is therefore normal that they are included in meaningful autobiographical memories. In Figure 3 the place is used to symbolize the memory contents: the individual's first camping holiday. 


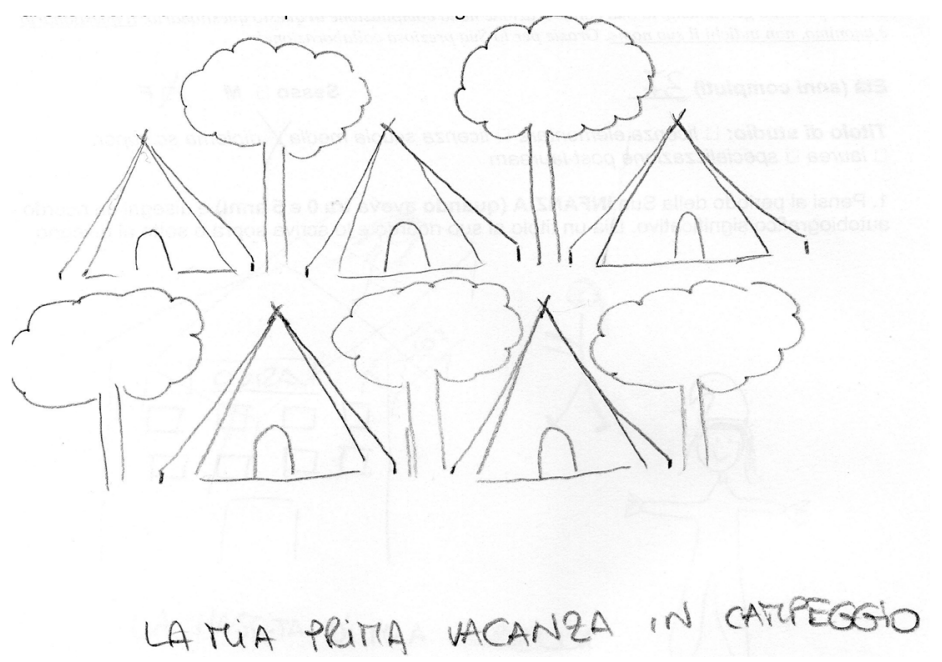

Figure 3. Drawing, referring to childhood, entitled "My first camping holiday".

The appearance in the drawings of so many holiday locations (from the sea to the mountains, to the lake, and to various Italian and foreign tourist towns) could be linked to the relationship between memory and emotions. After many years of research and experimentation, psychologists now agree that pleasant events, rather than neutral and unpleasant events, are easier to remember. The fact that half of the places related to adolescence are holiday locations, reveals that this age is especially remembered as a time of exploration and experimentation, thanks to the growing independence and the desire/need to build a new identity $[27,28]$. We found the importance of open spaces (such as playgrounds, gardens and woods) at any age, while one's own house and house of one's grandparents appears only in the recollections of infancy and childhood. Drawings referring to preadolescence highlight the importance of sports fields as they relate to group games. The swimming pool is a place remembered in reference to childhood, the age at which most people learn to swim and it is therefore most likely to be one of the events we have already defined as a "first time experience".

In Figure 4 we can see a drawing entitled "The first time we met in Paris," in which the social reference marker (boyfriend), place (Paris, symbolized by the Eiffel Tower) and "Qualia" (the typical emotions of love symbolized by the hearts and impressed by the facial expression of the characters).

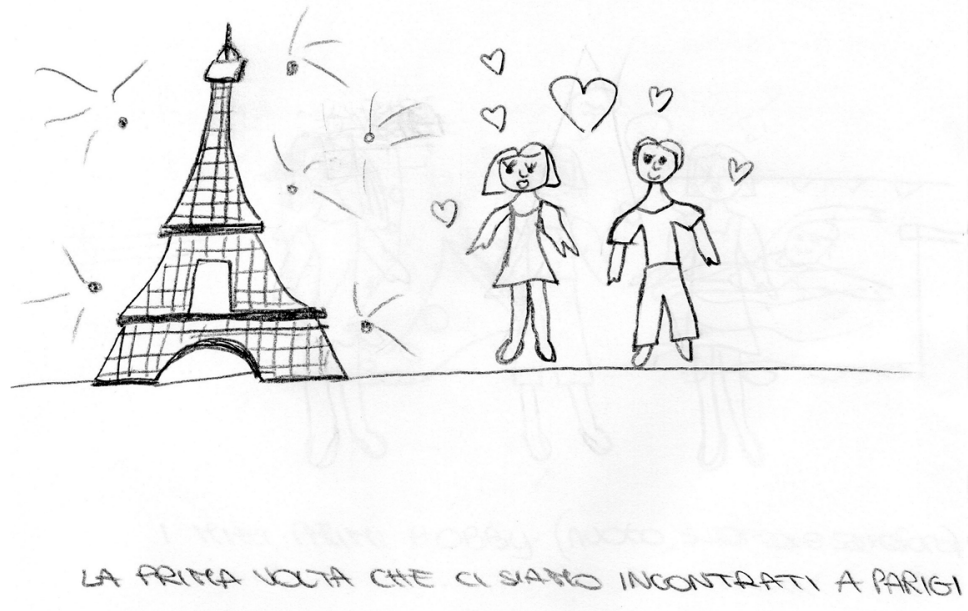

Figure 4. Drawing, referring to adolescence, entitled "The first time we met in Paris".

In regards to the indicator "Agency", we limit ourselves to reporting that it appears in 97 drawings and that the varied and different actions drawn by our subjects can be grouped into three main categories: A) actions related to interests and passions ("watching TV", "playing video games", 
"singing", etc.); B) actions related to habits ("having an afternoon snack", "studying", etc.), typical of the age considered; C) actions related to emotionally relevant events ("celebrating my tenth birthday", "travelling"), and early experiences ("the first time I rode my bicycle alone", "the first night I spent in Italy"). Even the marker "Commitment" was useful in our analysis: 19 drawing represent specific achievements and failures related to the selected different ages. This indicator is most present in adolescence, the age in which the person's drive is to experiment and to become more determined in the world thanks to the new cognitive and relational tools he or she possesses [27]. Percentages on the total of drawings for these last two markers can be seen in Table 6 .

Table 6. Markers "Agency" and "Commitment": percentages on the total of the drawings assigned to these two indicators (97 and 19, respectively).

\begin{tabular}{cccccc}
\hline & Infancy & Childhood & Pre-Adolescence & Adolescence & Total \\
\hline Agency (presence) & $17.5 \%$ & $27.8 \%$ & $32 \%$ & $22.7 \%$ & $33.9 \%$ \\
Commitment (presence) & $5.3 \%$ & $21 \%$ & $15.8 \%$ & $57.9 \%$ & $6.64 \%$ \\
\hline
\end{tabular}

Several participants have chosen to represent, as a meaningful memory, things such as, a particular school oral exam, the examination for their high school diploma, efforts to have a boyfriend or a girlfriend, obtaining their driver's license, etc. In Figure 5, the drawer of the memory, with a big smile of joy and pride, holds in her hands the evidence of two adolescence achievements she has obtained: her driver's license and her high school diploma.

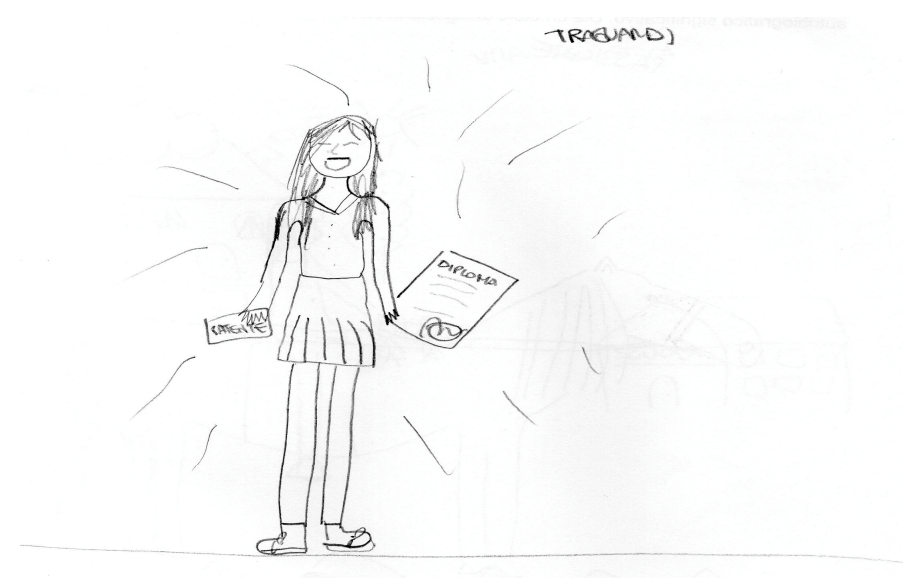

Figure 5. Drawing, referring to adolescence, entitled "Achievements".

In our view, a substantial result refers to the objects that appear in the drawings, in a few examples alone $(9.8 \%)$, in most cases within a context with characters and places $(90.2 \%)$, allowing the researcher to define better the representation. Objects, in some ways, help us to define who we are or have been in a certain age, and their memory follow us over time. In total, 116 objects were drawn in our study. In the pictures referring to infancy, we found specific toys $(32.6 \%)$ such as, puppets, dolls and toy cars, pointing to the importance they have, even in memory, those objects that according to Winnicott (1958) facilitate at this age the transition from a state of dependence on a caregiver to a greater autonomy, i.e., the "transactional objects" [29]. In second position there are swings and slides of children's playgrounds or kindergartens, structures that allow children unlimited motor games typical of this age and related to pleasure. In childhood memories, in addition to toys, slides and swings, there are also balls (10.7\%), television $(10.7 \%)$, bicycles $(7.1 \%)$, book bags $(7.1 \%)$, video games consoles $(7.1 \%)$, and other special items that marked this period of life, such as ballet shoes and tennis rackets. Among pre-adolescent memories there are books (35.7\%), musical instruments that were played (10.7\%), and electronic devices for listening to music such as Walkman, radio and computer (10.7\%). Adolescence is also remembered for the greatest autonomy need for displacements, as indicated by the appearance of mopeds (7.1\%), motorcycles $(7.1 \%)$, but especially of one's first car after getting his or her driver's license at the legal age of 18 years in Italy $(42.9 \%)$. In 
two drawings, the subjects depicted themselves with their high school diplomas just obtained and, because of the importance of one's body image at this age, in the work of a female individual appears the mirror, which generates unpleasant emotions in the character.

Regarding how people recall memories, interesting results come from the analysis of the responses to the semantic differential, referring to the three variables we considered: ease, pleasantness and speed in the recall of memories. For all the life ages considered, recovery was rated as "very" and "fairly" easy by the majority of respondents (with percentages for "very easy" between $52.8 \%$ for adolescence and $44,4 \%$ for pre-adolescence). We can therefore assume that the request to recall autobiographical memories through imagery hasn't certainly hindered the recall process, as the participants reported. To confirm this, the majority of the sample argued that the recollection of memories of the different periods was "very" and "fairly" fast (adding the two ways of response we get the percentages: $55.6 \%$ for childhood, $58.4 \%$ for childhood, $41.6 \%$ for pre-adolescence and $62.5 \%$ for adolescence). Even if it is true that it was not required a recollection of specific memories, but a choice among meaningful ones, this data could mean that using the figurative, besides the narrative, format at the time of recall is a fairly easy and fast way. Our data would confirm Rubin's (2003) thesis that mental pictures provide important memory help not only in the storage and organization of information, but also in the recall of the memories [11]. A greater variability in the responses result from the degree of pleasantness of the memories recalled. In particular, a significant difference was found between the pleasantness of recalling childhood memories and pre-adolescent ones $(t=2788$, $p<0.01$ ). Although most participants pleasantly recalled memories for all ages considered (with "very enjoyable" rates ranging between $66.7 \%$ and $47.2 \%$ ), recalling childhood memories was rated by the sample significantly more enjoyable than retrieving memories from pre-adolescence. This result can be related to the specific characteristics of pre-adolescence, highlighted by Erik Erikson's studies and recent research in cognitive neuroscience by Eveline Crone [27,28]. Pre-adolescence is an age of great bodily, psychological and social changes that are often experienced with ambivalent emotions. It is the age in which identity becomes more uncertain, facing a heavy reconstruction process based on physical and psychological-relational changes. As a result, recalling that period of life can be less pleasant than other periods of one's life story, such as childhood which in most people is a more stable itinerary of growth, and it is usually reconstructed and lived by adults as a happy and lucky period.

\section{Conclusions}

The present study is a further confirmation of the methodological potentialities of drawing in the autobiographical memory studies, but also gives the opportunity to reflect, starting from psychological literature, on the thematic content and the recall ways of autobiographical memories (in a sample of young adults), related to infancy, childhood, pre-adolescence and adolescence. Thanks to markers taken in part from previous research, it was possible to highlight several elements in the mental pictures that gave shape to the Self in every age, leaving traces in memory: specific social references, emotions and moods, places, actions and commitments, even meaningful objects. The recall of memories is rated by most of the research participants as easy, fast, and pleasant. However, a result that may be useful to explore with further research is the fact that the recall of pre-adolescent memories is rated less pleasant than that of childhood memories.

Acknowledgments: The study had no sources of funding. The author is grateful to the students of the Communication Studies course at Insubria University (Varese, Italy) who took part to the study voluntarily.

Conflicts of Interest: The author declares no conflicts of interest.

\section{References}

1. Palladino, P.; Vecchi, T. La memoria. In Psicologia Generale; Cherubini, P., Ed.; Cortina: Milano, Italy, 2012; pp. 205-241, ISBN 9788860304582.

2. Brewer, W.F. What is Autobiographical Memory? In Autobiographical Memory; Rubin, D.C., Ed.; Cambridge University Press: New York, NY, USA, 1986; pp. 25-49, ISBN 0521303222. 
3. Baddeley, A.D. What is Autobiographical Memory? In Theoretical Perspectives on Autobiographical Memory; Conway, M.A., Rubin, D.C., Spinnler, H., Wagenaar, W.A., Eds.; Kluwer Academic Publishers: Dordrecht, The Netherlands, 1992; pp. 13-29, ISBN 9789048141364.

4. Cabeza, R.; St. Jacques, P.L. Functional Neuroimagining of Autobiographical Memory. Trends Cogn. Sci. 2007, 11, 219-227, doi:10.1016/j.tics.2007.02.005.

5. Schacter, D.L. Alla Ricerca Della Memoria; Einaudi: Torino, Italy, 2001; ISBN 8806157132.

6. Mammarella, N.; Di Domenico, A. Memoria Autobiografica; Carocci: Roma, Italy, 2011; ISBN 9788843060177.

7. Giani Gallino, T. La costruzione dell'identità del Sé nell'infanzia. Affetti e memoria visuo-spaziotemporale. Età Evol. 2003, 76, 17-32.

8. Giani Gallino, T. Quando ho Imparato ad Andare in Bicicletta. Memoria Autobiografica e Identità del Sé; Cortina: Milano, Italy, 2004; ISBN 9788870788716.

9. Paivio, A. Imagery and Verbal Processes; Holt, Rinehart, and Winston: New York, NY, USA, 1971; ISBN 0030851734.

10. Kosslyn, S.M. Ghosts in the Mind Machine; Norton \& Co.: New York, NY, USA, 1983; ISBN 0393952576.

11. Rubin, D.C. Autobiographical memory. In Encyclopedia of Cognitive Science; Nadel, L., Ed.; Nature Publishing Group: London, UK, 2003; Volume 1, pp. 286-289; ISBN 0333792610.

12. Conway, M.A.; Loveday, C. Remembering, Imagining, False Memories \& Personal Meaning. Conscious. Cogn. 2015, 33, 574-581, doi:10.1016/j.concog.2014.12.002.

13. Greenberg, D.L.; Rubin, D.C. The Neuropsychology of Autobiographical Memory. Cortex 2003, 39, 687-728, doi:10.1016/S0010-9452(08)70860-8.

14. Tulving, E. The Origin of Autonoesis in Episodic Memory. In The Nature of Remembering: Esseys in Honor of Robert G. Crowder; Roediger, H.L., Nairne, J.S., Suprenant, A.M., Eds.; American Psychological Association: Washington, DC, USA, 2001; pp. 17-34, ISBN 1557987505.

15. Osgood, C.E.; Suci, C.J.; Tannembaum, P.H. The Measurement of Meaning; University of Illinois Press: Urbana, IL, USA, 1957; ISBN 0252745396.

16. Bruner, J.S. Self-Making and World-Making. J. Aesthet. Educ. 1991, 25, 67-78, doi:10.2307/3333092.

17. Bruner, J.S. A Narrative Model of Self-Construction. Ann. N. Y. Acad. Sci. 1997, 818, 145-161, doi:10.1111/j.1749-6632.1997.tb48253.x.

18. Confalonieri, E.; Scaratti, G. Storie di Crescita. Approccio Narrative e Costruzione del Sé in Adolescenza; Unicopli: Milano, Italy, 2000; ISBN 8840006184.

19. Cohen, J.A. Coefficient of Agreement for Nominal Scales. Educ. Psychol. Meas. 1960, 20, 37-46, doi:10.1177/001316446002000104.

20. Freud, S. Repression (1915). In The Standard Edition of the Complete Psychological Works of Sigmund Freud; Strachey, J., Ed.; Hogarth Press and The Institute of Psychoanalysis: London, UK, 1957; Volume 14, pp. 143158, ISBN 0099426676.

21. Conway, M.A. Episodic Memory. Neuropsychologia 2009, 47, 2305-2313, doi:0.1016/j.neuropsychologia. 2009.02.003

22. Conway, M.A.; Rubin, D.C. The Structure of Autobiographical Memory. In Theories of Memory; Collins, A.F., Gathercole, S.E., Conway, M.A., Morris, E.M., Eds.; Erlbaum: Hove, UK, 1993; pp. 103-138, ISBN 086377290.

23. Robinson, J.A.; Swanson, S. Autobiograhical Memory: The Next Phase. Appl. Cogn. Psychol. 1993, 4, 321335, doi:10.1002/acp.2350040407.

24. Talarico, J.M.; Labar, K.; Runin, D.C. Emotional Intensity Predicts Autobiographical Memory Experience. Mem. Cogn. 2004, 32, 1118-1132, doi:10.3758/BF03196886.

25. Wood, W.J.; Conway, M.A. Subjective Impact, Meaning Making and Current and Recalled Emotions for Self Defining Memories. J. Personal. 2006, 74, 811-845, doi:10.1111/j.1467-6494.2006.00393.x.

26. Brofenbrenner, U.; Morris, P.A. The Bioecological Model of Human Development. In Handbook of Child Psychology, 6th ed.; Damon, W., Lerner, R.M., Eds.; Wiley: New York, NY, USA, 2006; Volume 1, pp. 793828, ISBN 0471272884.

27. Erikson, E.H. Childhood and Society; Norton \& Co.: New York, NY, USA, 1950; ISBN 039331068X. 
28. Crone, E.A. The Adolescent Brain. Changes in Learning, Decision-Making and Social Relations; Routledge: Abingdon-on-Thames, UK, 2017; ISBN 9781138855953.

29. Winnicott, D.W. Collected Papers: Through Paediatrics to Psycho-Analysis; Tavistock Publications: London, UK, 1958; ISBN 0422710709.

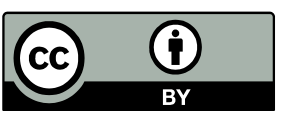

(C) 2017 by the authors. Licensee MDPI, Basel, Switzerland. This article is an open access article distributed under the terms and conditions of the Creative Commons Attribution (CC BY) license (http://creativecommons.org/licenses/by/4.0/). 